\title{
Selection of Area Suitable for Performing Partial-Depth Repair of Corner Damage of Concrete Paving Slab Under Wheel Load
}

\author{
Chau Lee \\ Professor, Department of Civil-Engineering, National Central University, Chung-Li, Taiwan 32054., \\ chaulee@cc.ncu.edu.tw \\ Xin-Hua Huang \\ Ph.D. Candidate, Department of Civil-Engineering, National Central University, Chung-Li, Taiwan 32054. \\ Jhao-Bin Lin \\ M.S., Department of Civil-Engineering, National Central University, Chung-Li, Taiwan 32054.
}

Follow this and additional works at: https://jmstt.ntou.edu.tw/journal

Part of the Civil and Environmental Engineering Commons

\section{Recommended Citation}

Lee, Chau; Huang, Xin-Hua; and Lin, Jhao-Bin (2004) "Selection of Area Suitable for Performing Partial-Depth Repair of Corner Damage of Concrete Paving Slab Under Wheel Load," Journal of Marine Science and Technology: Vol. 12: Iss.

1, Article 7.

DOI: $10.51400 / 2709-6998.2220$

Available at: https://jmstt.ntou.edu.tw/journal/vol12/iss1/7

This Research Article is brought to you for free and open access by Journal of Marine Science and Technology. It has been accepted for inclusion in Journal of Marine Science and Technology by an authorized editor of Journal of Marine Science and Technology. 
Selection of Area Suitable for Performing Partial-Depth Repair of Corner Damage of Concrete Paving Slab Under Wheel Load

Acknowledgements

The authors would like to thank the Taiwan Area National Freeway Bureau for financially supporting this research under Contract No. 088B5AS003B5A004. 


\title{
SELECTION OF AREA SUITABLE FOR PERFORMING PARTIAL-DEPTH REPAIR OF CORNER DAMAGE OF CONCRETE PAVING SLAB UNDER WHEEL LOAD
}

\author{
Chau Lee*, Xin-Hua Huang**, and Jhao-Bin Lin***
}

Key words: concrete pavement, repair, finite element.

\section{ABSTRACT}

This study reveals the characteristics of using different repair materials and different repair outline designs for the partial-depth repair of the damage to corners of concrete paving slabs under wheel load. 3D finite element models were used to study how the changes to the outlines of the repaired area affect the maximum-stress and lowstress proportions in concrete elements that are attached to repaired interface when different repairing materials are used. The results indicate that the maximum stress increased but the proportion of lowstress shrank as the repaired area became larger. When cementitious repair materials were used, the depth of a square shaped repair area seemed to govern the effectiveness of the repair more strongly than does the side length. Epoxy mortar was not appropriate for use in square repaired areas, but could be used in small spherically shaped repair areas. Epoxy mortar was more effectively used in shallow repairs than in deep repairs.

\section{INTRODUCTION}

Corner damage is a common problem in jointed concrete pavements (JCP). It decreases the serviceability of the pavement and can be hazardous to highway users. Unsuitable repairing of such damage may result in accelerated pavement deterioration [18]. The Federal Highway Administration (FHWA), the American Concrete Pavement Association (ACPA), the National Cooperative Highway Research Program (NCHRP) and the Strategic Highway Research Program (SHRP) have all provided good guidelines for making partial-depth repairs [17].

Paper Submitted 11/05/03, Accepted 12/16/03. Author for Correspondence: Chau Lee. E-mail: chaulee@cc.ncu.edu.tw.

*Professor, Department of Civil-Engineering, National Central University, Chung-Li, Taiwan 32054.

**Ph.D. Candidate, Department of Civil-Engineering, National Central University, Chung-Li, Taiwan 32054.

***M.S., Department of Civil-Engineering, National Central University, Chung-Li, Taiwan 32054.
In brief, partial-depth spall repair involves removing the deteriorated concrete that is limited to the top one-third of the slab thickness and replacing it with a suitable repair material $[6,18]$. The patching material should not contact reinforcing steel or load transfer devices $[6,21]$. The saw-and-patch procedure is commonly used in partial-depth repair. It involves firstly saw-cutting the pavement to the appropriate depth, removing the deteriorated concrete, and replacing it with an appropriate patching material $[8,20,21]$. The repair boundaries should be square or rectangular because irregular shapes and internal corners tend to cause cracking of the patch material $[6,20]$. If the spall is located at the corner of the slab, then the minimum recommended depth is 2 in $(51 \mathrm{~mm})$, the minimum patch length is 10 in $(254 \mathrm{~mm})$ and the minimum width is 4 in $(102 \mathrm{~mm})[6,21]$. A high proportion of repair projects require patches to be opened to traffic within 4 to 6 hours, so a wide variety of rapidly setting and/or high early-strength patching materials are used for such projects. Type III cement with or without admixtures and epoxy resin mortar or concrete have been used for making rapid repairs $[8,10]$.

Finite element analysis is a powerful tool for researching and designing pavements. Two-dimensional finite element programs such as ILLI-SLAB and KENSLAB have been used in the past two decades to calculate stress in concrete pavements. In recent years, three-dimensional finite element analysis has provided responses of pavements that cannot be revealed by traditional 2D programs [9]. Many computational studies of JCP behavior have been based on 3D finite element analysis. For example, Ioannides and Donelly [12] built a 3D model for analyzing static wheel load. Chatti [4] modeled dowels using beam elements and employed the contact between the concrete slab and the ground to analyze the response under dynamic wheel load. Channakeshava and Bargezar [3] considered the interaction between the dowels and the concrete. Kuo [15] developed the 3DPAVE model to determine simul- 
taneously the static wheel load and non-linear effects of temperature. Massad et al. [16] used solid type foundation to study the variation of temperature of JCP. Shoukry et al. [19] modeled dowels using solid elements meshed within the solid slab to analyze dynamic wheel load and non-linear temperature effects.

Although most investigators have developed pioneering techniques to model pavements, the distribution of stress on repaired areas of concrete paving slabs following partial-depth repair has not been addressed. Suitable patching materials and methods of repair must be chosen to ensure that repairs are effective and thus avoid having to repair repeatedly corner damage to concrete paving slabs. This study attempts to select appropriate shapes and sizes of partial-depth repairs to corners by using 3D finite element method in consideration of different patching materials under wheel load.

\section{MODELING STRATEGY AND VALIDATION}

ANSYS v5.7 was used to develop 3D finite element models to simulate the response of partial-depth repair of the corners of JCPs under wheel load. The variations of stresses at the interface between the original concrete and the repairing material, generated by wheel load, were examined. Spring elements with gapping ability were employed to model the Winkler foundation with partial contact ability. To save CPU time, the load transfer devices such as dowel bars or aggregate interlocks between adjacent slabs were modeled by vertical spring elements that provided a vertical force without any moment constraint. This conventional assumption is based on earlier investigations revealed that the primary dowel mechanism of load transfer is shear, while the contribution of bending and torsion is less than $5 \%$, provided the deflection load transfer efficiency $\left(\mathrm{LTE}_{\delta}\right)$ exceeds approximately $80 \%$ [13].

Table 1 lists the types of elements used in this study. The element aspect ratio was maintained at under $5: 1$ to reduce the probability of shear locking [7], and more than four mesh divisions were used through the depth of the slab to minimize the hourglass behavior [1]. Preliminary studies were conducted before parametric analysis to check the basic settings and verify the model.

\section{PRELIMINARY STUDY}

\section{Single Slab Model}

The single slab model, presented in Fig. 1(a), consists of two parts. The main part represents undamaged concrete, and the core is the area to be repaired. The core part was near one corner of the slab, and had the fineness of the mesh in that part was the same as in the main part.

The maximum tensile stress and the maximum corner deflection calculated by the studied model under various load areas were compared with those obtained by Westergaard's equation [11]. According to Table 2, the results were reasonably consistent. Hence, the studied model was accepted.

\section{Four-slab Model}

A four-slab model with load transfer devices between adjacent slabs, indicated in Fig. 1(b), was established to check the load transfer settings. The shear transfer behavior was simplified to a series of vertical springs; the transverse joint stiffness was set to 690 MPa (100,000 psi) and the longitudinal joint stiffness was $218 \mathrm{MPa}(31,570 \mathrm{psi})$ [11]. The core and main parts

Table 1. Elements used in developing models

\begin{tabular}{|c|c|c|c|c|}
\hline \multirow{2}{*}{ Analysis type } & \multicolumn{4}{|c|}{ Parts of model } \\
\hline & Load transfer & Slab & Base & Wheel-slab contact \\
\hline Single slab & $\begin{array}{c}\text { Slab edges were } \\
\text { assumed to be free. }\end{array}$ & & & \\
\hline Multi-slab & $\sum_{\text {Spring elements }}$ & $\begin{array}{l}8 \text { nodes, 3-D space, } \\
\text { each node had DOF } \\
\text { of UX, UY and UZ. }\end{array}$ & $\begin{array}{c}\frac{\bar{F}}{\sqrt{\text { Spring elements }}} \\
\text { with gap options }\end{array}$ & $\begin{array}{l}\text { Surface to surface } \\
\text { contact (contact } \\
\text { behavior was set to } \\
\text { be always bonded) }\end{array}$ \\
\hline
\end{tabular}


Table 2. Comparisons for results in preliminary study

\begin{tabular}{clcc}
\multicolumn{4}{c}{ Single-slab Model } \\
\hline $\begin{array}{c}\text { Load area } \\
\left(\mathrm{m}^{2}\right)\end{array}$ & \multicolumn{1}{c}{ Method } & $\begin{array}{c}\text { Maximum tensile } \\
\text { stress }(\mathrm{Pa})\end{array}$ & $\begin{array}{c}\text { Maximum corner } \\
\text { deflection }\left(10^{-3} \mathrm{~m}\right)\end{array}$ \\
\hline 0.05 & ANSYS (This study) & $1.16 \times 10^{6}$ & 0.884 \\
& Westergaard & $1.13 \times 10^{6}$ & 0.943 \\
0.20 & ANSYS (This study) & $7.84 \times 10^{5}$ & 0.711 \\
& Westergaard & $7.15 \times 10^{5}$ & 0.773 \\
0.45 & ANSYS (This study) & $4.80 \times 10^{5}$ & 0.537 \\
& Westergaard & $4.80 \times 10^{5}$ & 0.622 \\
\hline
\end{tabular}

Four-slab Model

\begin{tabular}{|c|c|c|c|c|}
\hline \multirow[b]{2}{*}{ Method } & \multicolumn{2}{|c|}{ Minimum joint efficiency } & \multirow[b]{2}{*}{$\begin{array}{l}\text { Maximum tensile } \\
\text { stress }(\mathrm{Pa})\end{array}$} & \multirow[b]{2}{*}{$\begin{array}{l}\text { Maximum corner } \\
\text { deflection }\left(10^{-3} \mathrm{~m}\right)\end{array}$} \\
\hline & $\begin{array}{c}\text { Transverse } \\
(\%)\end{array}$ & $\begin{array}{c}\text { Longitudinal } \\
(\%)\end{array}$ & & \\
\hline ANSYS (This study) & 87 & 63 & $3.26 \times 10^{5}$ & 0.241 \\
\hline KENSLAB & 84 & 60 & $3.58 \times 10^{5}$ & 0.244 \\
\hline ILLI-SLAB & 85 & 61 & $3.51 \times 10^{5}$ & 0.246 \\
\hline
\end{tabular}

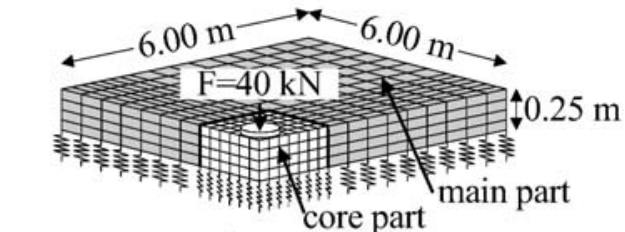

$\mathrm{K}=54.3 \mathrm{MN} / \mathrm{m}^{3}(200 \mathrm{pci})$

Concrete Slab: $\mathrm{E}=34.5 \mathrm{GPa}, v=0.2$

Load area $=0.05 \mathrm{~m}^{2}, 0.20 \mathrm{~m}^{2}, 0.45 \mathrm{~m}^{2}$

(a) Single-slab model

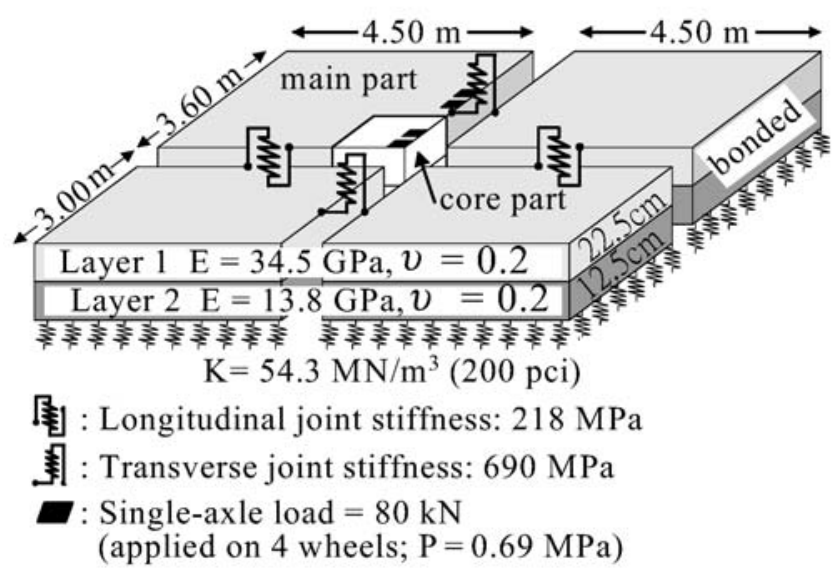

(b) Four-slab model

Fig. 1. Illustration for models in preliminary study. had meshes of the same fineness. This four-slab model was a trial foundation on which to build nine-slab model for parametric analysis, as will be described later.

The results obtained by the four-slab model were compared with those calculated using KENSLAB and ILLI-SLAB. As shown in Table 2, the results of the two computer programs were agreed closely with those of the four-slab model. Therefore, the basic settings and assumptions of the four-slab model were used in parametric analysis.

\section{PARAMETRIC ANALYSIS}

Model Configuration A single slab model and a nine-slab model were established by parametric analysis, as shown in Figs. 2(a) and 2(b), respectively. The basic settings of the two models were similar to those in the models verified in preliminary studies, but the stiffness of all joints in the nine-slab model was $690 \mathrm{MPa}$ $(100,000 \mathrm{psi})$ [2]. This uniform joint stiffness eliminated the effect of varying load transfer and offered a normal standard by which to compare the stress characteristics on the area of interest. The resulting average deflection load transfer efficiency $\left(\mathrm{LTE}_{\delta}\right)$ under this joint stiffness was found to be approximately $94 \%$.

In single slab analysis, the core is divided and meshed into three shapes with different side lengths and depths, as indicated in Fig. 3. The square case simulates a typical saw-and-patch repair technique; the triangular shape corresponds to a diagonal corner saw cut repair and the spherical case simulates the clean-and-patch 
technique.

In the nine-slab model, the core is divided and meshed into squares. Fig. 3(a) depicts the side length and the depth of the repairs. These mesh techniques enable the stress distribution on the interface of the concrete with repair material in the area of partial-depth repairs under a wheel load to be analyzed. The interface between the original concrete and the repairing material was assumed to be fully bonded without any separation or sliding.

Normal concrete, high early-strength concrete, and epoxy mortar were used as repairing materials in the analysis. Table 3 presents the material properties obtained from actual tests [14].

\section{Loadings}

A single wheel load with a tire pressure of 6.67 $\times 10^{5} \mathrm{~Pa}$ and a tire print of $0.3 \mathrm{~m} \times 0.2 \mathrm{~m}$ was applied to the corner of the core. The effect of gravity on the concrete slab and the repairing material was considered.

\section{Criteria for Comparing Stress States}

The repaired areas consisted of different materials

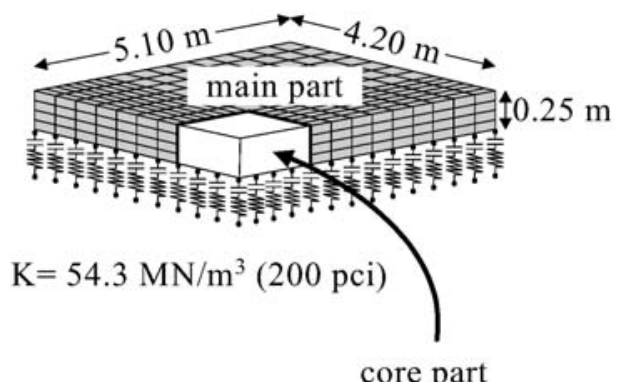

(Fig. 3 for detail)

(a) Single-slab model

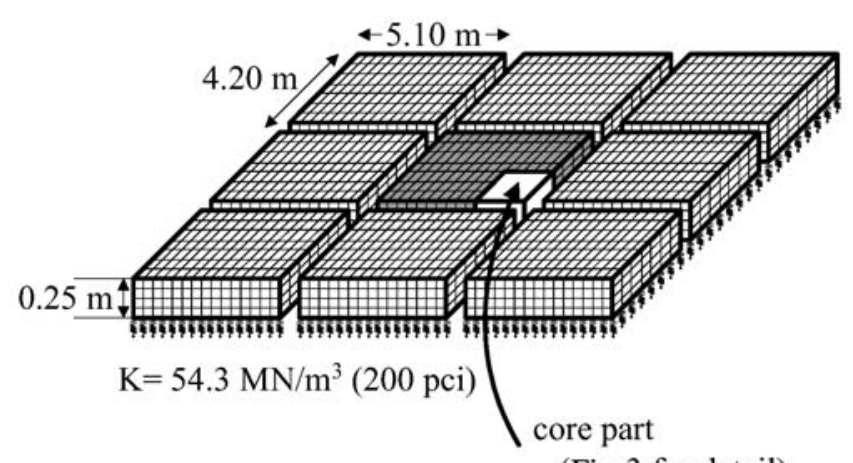

(Fig. 3 for detail)

(b) Nine-slab model and had different trends of interfaces, so elucidating the characteristics of stress distribution on the region of interest, using either principal stress or shear stress, individually, was difficult. The maximum first principal stresses $\left(S_{1}\right)$ and von Mises stresses $\left(\sigma^{\prime}\right)$ among the elements of the original concrete attached to the repair interface were recorded following each calculation. The aforementioned region is of interest because each repair material has different strain characteristics under load, and determining the stress values on the elements of the original concrete attached to the repair interface can eliminate the confusion caused by using different repair materials with various strain characteristics, during the evaluation of the effects of these parameters on the original concrete.
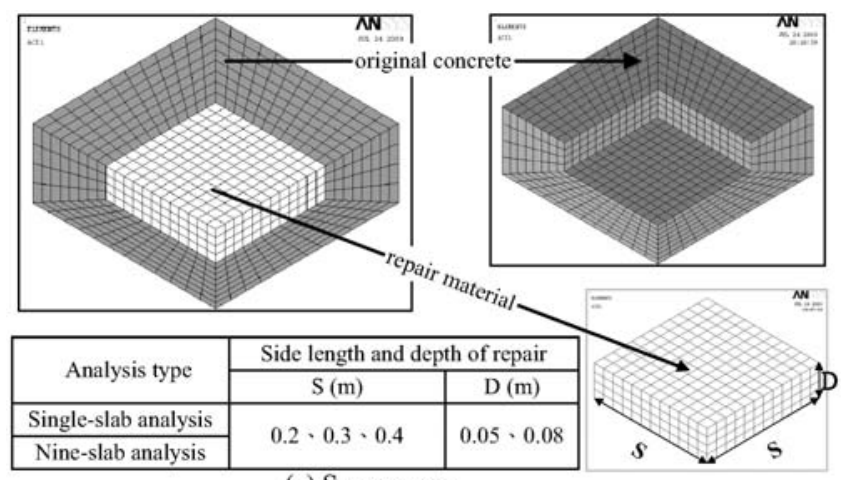

(a) Square area

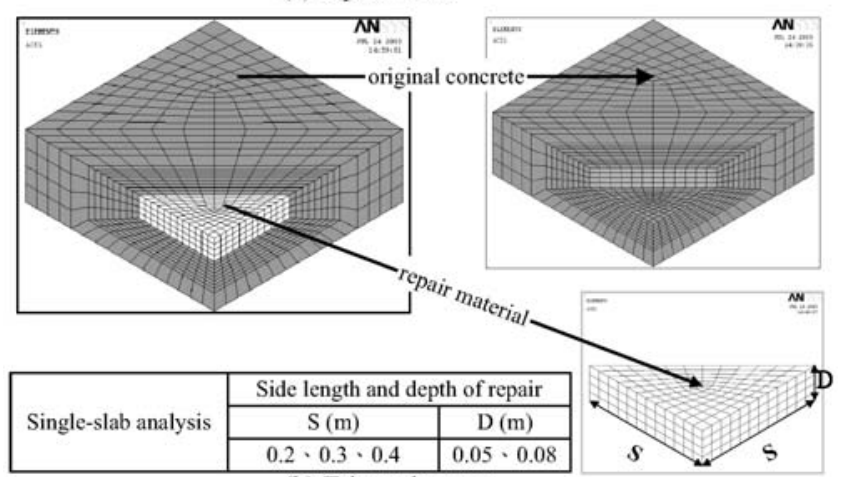

(b) Triangular area

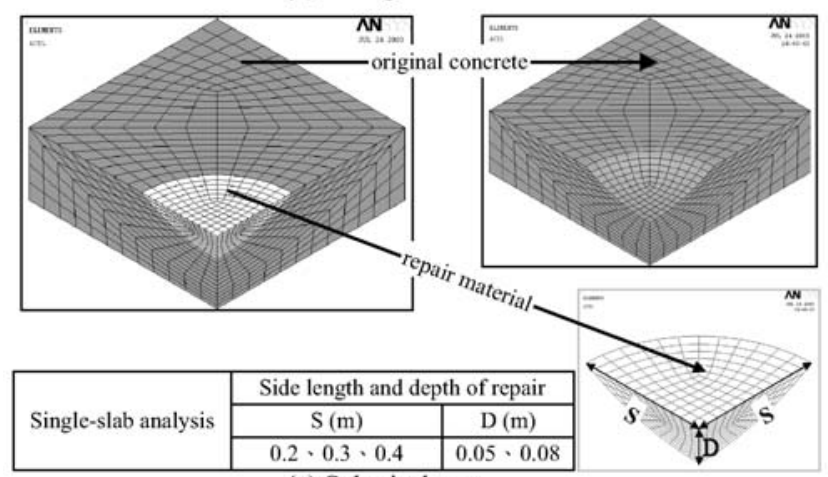

(c) Spherical area

Fig. 2. Illustration for models in parametric study.

Fig. 3. Details and variables in core part. 
Table 3. Material properties used in parametric study

\begin{tabular}{lcccc}
\hline & & \multicolumn{3}{c}{ Repair material } \\
\cline { 3 - 5 } Material properties & $\begin{array}{c}\text { Concrete slab } \\
\text { (Normal concrete) }\end{array}$ & Normal concrete & $\begin{array}{c}\text { High early strength } \\
\text { concrete }\end{array}$ & $\begin{array}{c}\text { Epoxy } \\
\text { mortar }\end{array}$ \\
\hline Young's modulus $\left(\mathrm{N} / \mathrm{m}^{3}\right)$ & $2.4 \times 10^{10}$ & $2.4 \times 10^{10}$ & $2.5 \times 10^{10}$ & $1.1 \times 10^{10}$ \\
Poisson ratio & 0.158 & 0.158 & 0.142 & 0.285 \\
Unit weight $\left(\mathrm{kg} / \mathrm{m}^{3}\right)$ & 2,300 & 2,300 & 2,300 & 1,200 \\
\hline
\end{tabular}

The first principal stress $\left(S_{1}\right)$ is that with the highest positive value (algebraically largest value) among the three principal stresses derived from each element after the analysis. The first principal stress was considered to study tensile effects on the areas of interest.

Von Mises stress $\left(\sigma^{\prime}\right)$ is derived from

$$
\sigma^{\prime}=\sqrt{\frac{\left(\sigma_{1}-\sigma_{2}\right)^{2}+\left(\sigma_{2}-\sigma_{3}\right)^{2}+\left(\sigma_{3}-\sigma_{1}\right)^{2}}{2}}
$$

where $\sigma_{1}, \sigma_{2}$ and $\sigma_{3}$ are the principal stresses. According to the distortion energy theory, failure is predicted to occur in the multiaxial state of stress when the distortion energy per unit volume becomes equal to or exceeds the distortion energy per unit volume at the time of failure in a simple uniaxial stress test on a specimen of the same material [5]. Von Mises stresses were taken as references for comparing the relative shear influence on the elements of the interested area. The primary aim of this work was to study trends in the distribution of stress among the elements of interest, so failure of the interested area was not addressed.

The low-stress proportion was measured following each analysis to estimate the stability of bonding. The low-stress proportion was defined as the percentage of elements in the original concrete attached to the bonding interface with a stress lower than the low-stress level. The low-stress level was defined as $8.58 \times 10^{5} \mathrm{~Pa}$ $\left(8.75 \mathrm{~kg} / \mathrm{cm}^{2}\right)$, which was $25 \%$ of the tensile strength of the original concrete, which was assumed to be $3.43 \times$ $10^{6} \mathrm{~Pa}\left(35 \mathrm{~kg} / \mathrm{cm}^{2}\right), 10 \%$ of the supposed concrete compressive strength of $3.43 \times 10^{7} \mathrm{~Pa}\left(350 \mathrm{~kg} / \mathrm{cm}^{2}\right)$. According to test data obtained by several researchers, the original concrete is expected not to fail by fatigue when the stress ratio is below 0.5 [11]. Therefore, the low-stress level, corresponding to a ratio of 0.25 of the tensile strength, assumed herein is conservative. The proportion of low stress was measured approximately from the computer screen because the mesh of interested area was formed with brick elements of known sizes and uniform length. The low-stress proportion was adopted as a reference to compare the relative bonding stability of the repaired area. A larger lowstress proportion generates a more stable bonding interface.

\section{Results of Single-Slab Model}

Figure 4 shows the maximum first principal stress $\left(S_{1}\right)$ and the maximum Von Mises stress $(\sigma)$, and Fig. 5 shows the low-stress proportions obtained from the single-slab model.

\section{Use of Cementitious Concretes as Repairing Materials}

The material properties of cementitious repairing materials, normal concrete and high early-strength concrete, were similar to each other, and to those of the original concrete.

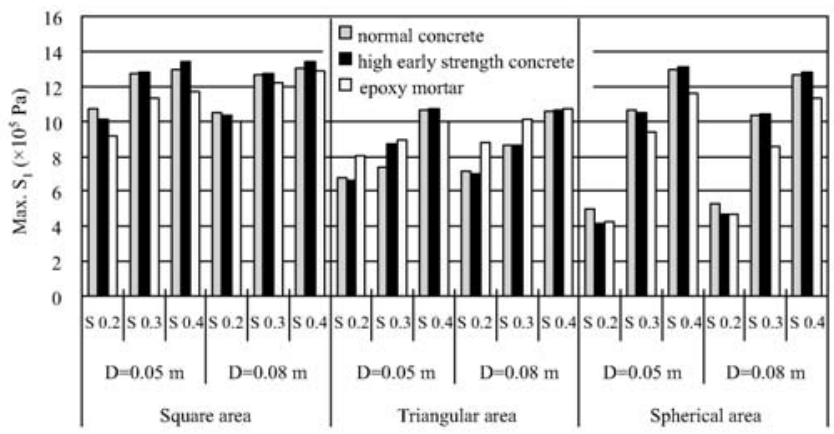

(a) Maximum $\mathrm{S}_{\mathrm{I}}$

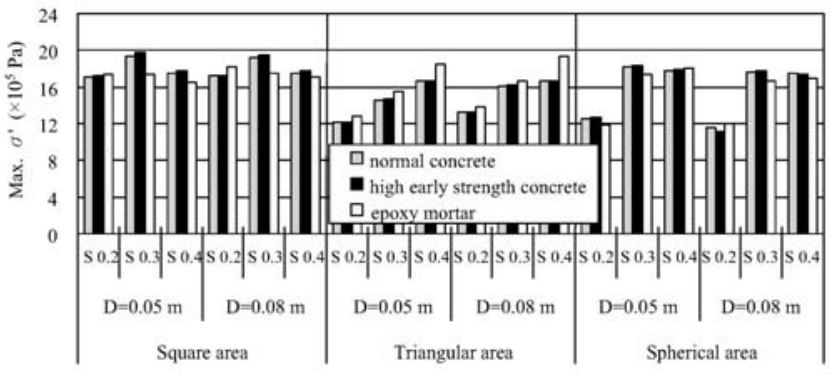

(b) Maximum $\sigma^{\prime}$

Fig. 4. Maximum stresses obtained from single-slab model. 


\section{Square Repaired Area}

As Fig. 4(a) shows, increasing the side length of repair from 0.2 to $0.4 \mathrm{~m}$ increased the maximum $S_{1}$ by approximately $30 \%$. However, this increase in maximum $S_{1}$ was insignificant when the side length of repair exceeded $0.3 \mathrm{~m}$. The value of $\sigma^{\prime}$ was maximum when the side length of repair was about $0.3 \mathrm{~m}$, regardless of the influence of the depth of the repair, as shown in Fig. 4(b). $S_{1}$ and $\sigma$ were typically maximum around the upper intersection of the vertical repairing boundaries, as presented in Fig. 6(a). Increasing the side length of repair reduced the low-stress proportions of both $S_{1}$ and $\sigma^{\prime}$, as indicated in Figs. 5(a) and 5(b). In addition, increasing the depth of repair slightly increased the low-stress proportions of both $S_{1}$ and $\sigma^{\prime}$. This increase becomes greater as the side length of repair is enlarged.

Therefore, square repairing areas yield more benefit as depth, rather than area is increased, when cementitious materials are used.

\section{Triangular Repaired Area}

Figures 4(a) and 4(b) reveal that a larger side length of repair corresponds to higher maximum values of $S_{1}$ and $\sigma^{\prime}$.

$S_{1}$ and $\sigma^{\prime}$ were usually maximum near the middle of the hypotenuse of the area of repair on the slab
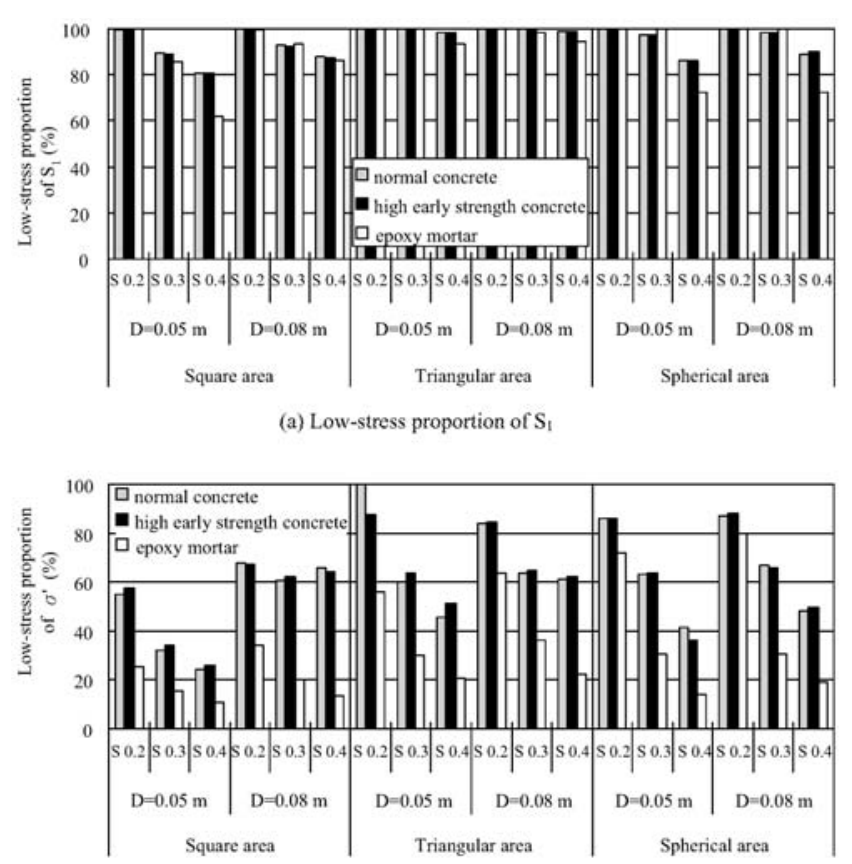

(b) Low-stress proportion of $\sigma^{\prime}$

Fig. 5. Low-stress proportions obtained from single-slab model. surface, as depicted in Fig. 6(c). The low-stress proportions of $\sigma^{\prime}$ decreased as the side lengths of repair increased, as shown in Fig. 5(b). The low-stress proportion of $S_{1}$ on the triangular area of repair was larger than that on areas with other shapes, as indicated in Fig. 5(a).

In conclusion, triangular areas of repair are more effective when the side length of repair is small. When cementitious materials were used, triangular areas of repair suffer less from tensile effects because of their low-stress proportions of $S_{1}$ are larger than those of the areas of repair with other shapes.

\section{Spherical Repaired Area}

Figure 4(a) illustrates that increasing the side length of repair for spherically shaped areas significantly increased the maximum $S_{1}$ values. The maximum $S_{1}$ value on a spherical area was smaller than that on areas of repair with other shapes when the side length of repair was reduced to $0.2 \mathrm{~m}$. The value of $\sigma^{\prime}$ was

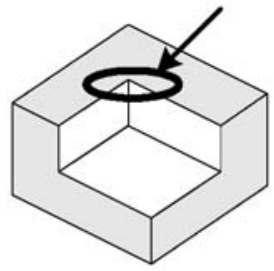

(a)

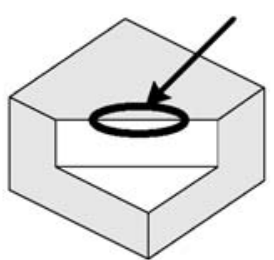

(c)

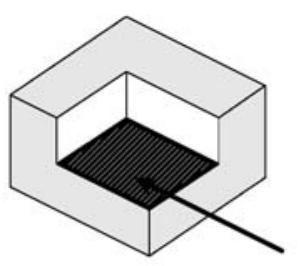

(b)

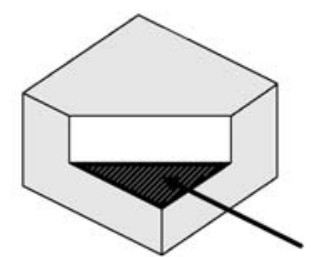

(d)

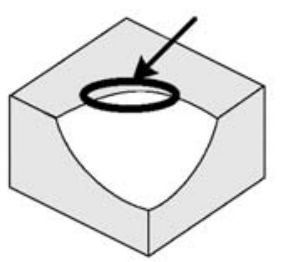

(e) 
maximum when the side length of repair was around $0.3 \mathrm{~m}$, as shown in Fig. 4(b). $S_{1}$ and $\sigma^{\prime}$ were normally maximum around the middle of the arc of the spherical repairing boundaries on the slab surface, as plotted in Fig. 6(e). The low-stress proportions of both $S_{1}$ and $\sigma^{\prime}$ declined as the side length of repair increased, as shown in Figs. 5(a) and 5(b).

In summary, the maximum values associated with $S_{1}$ and $\sigma$ were significantly reduced when side length of the spherical area of repair was reduced to $0.2 \mathrm{~m}$. Thus, the spherical area was expected to be more effective for small side length repairs that use cementitious repairing materials.

\section{Use of Epoxy Mortar as Repairing Material}

The differences between the material properties of epoxy mortar and the original concrete are significant, so some of the results appear to be anomalous, when considered in relation to those for cementitious repairing materials.

\section{Square Repaired Area}

As shown in Fig. 4(a), the maximum $S_{1}$ increased with the side length of repair. Increasing the depth of repair increased the maximal $S_{1}$ and $\sigma^{\prime}$, as explicated in Figs. 4(a) and 4(b).

$S_{1}$ and $\sigma^{\prime}$ were usually maximum near the bottom of the repaired area, as shown in Fig. 6(b). The lowstress proportions of $S_{1}$ and $\sigma^{\prime}$ declined as the side length of repair increased, as shown in Figs. 5(a) and 5 (b). Moreover, increasing the depth of repair increased the low-stress proportions of both $S_{1}$ and $\sigma^{\prime}$, as shown in Figs. 5(a) and 5(b).

Therefore, increasing the depth of a square area of repair not only caused disadvantageous influence in increasing the maximal $S_{1}$ and $\sigma^{\prime}$, but also caused beneficial influence in increasing the low-stress proportions of both $S_{1}$ and $\sigma^{\prime}$. These results imply that epoxy mortar does not serve well when square areas are used for partial-depth repair.

\section{Triangular Repaired Area}

Figures 4(a) and 4(b) indicate that the maximum values of $S_{1}$ and $\sigma^{\prime}$ were varied in proportion to the side length of repair. Increasing the depth of the repair increased both the maximum $S_{1}$ and the maximum $\sigma^{\prime}$ values.

$S_{1}$ was maximum on the bottom of the repaired area, and $\sigma^{\prime}$ was maximum around the middle of hypotenuse of the repaired area on the surface of the slab, as shown in Figs. 6(d) and 6(c), respectively. When the side length of repair was larger than $0.3 \mathrm{~m}$, the lowstress proportion of $S_{1}$ was decreased as the side length of repair increased, as shown in Fig. 5(a). The lowstress proportion of $\sigma^{\prime}$ was decreased as the side length of repair increased, as shown in Fig. 5(b). Moreover, the low-stress proportion of $\sigma^{\prime}$ increased with the depth of the repair, as indicated by Fig. 5(b).

In summary, a triangular area of repair is preferred for small repair side length when epoxy mortar is used.

\section{Spherical Repaired Area}

Figure 4(a) shows that increasing the side length of repair for spherical areas of repair significantly increased maximum $S_{1}$ values. The maximum $S_{1}$ and $\sigma$ in a spherical area of repair were less than those in areas of repair with other shapes when the side length of repair was small - for example $0.2 \mathrm{~m}$ - as shown in Figs. 4(a) and 4(b).

$S_{1}$ and $\sigma$ were maximal near the middle of the arc of the spherical repair boundary on the surface of the slab, as depicted in Fig. 6(e). The low-stress proportions of $S_{1}$ and $\sigma^{\prime}$ generally decreased as the side length of repair increased, as indicated in Figs. 5(a) and 5 (b).

In conclusion, spherical areas are preferred for a small side length of repair, when epoxy mortar is used. A smaller side length of a spherical repair provided superior bonding stability because it yielded larger lowstress proportions of both $S_{1}$ and $\sigma^{\prime}$ simultaneously.

\section{Results of Nine-slab Model}

Square areas of repair, used commonly in partialdepth repairs, were applied in an analysis to understand the differences between the single-slab model and the nine-slab model. Figs. 7 and 8 compare the respective maximum stresses and the low-stress proportions.

The maximum stress values of $S_{1}$ and $\sigma^{\prime}$ on the areas of repair, obtained using the nine-slab model were smaller than those obtained using the single-slab model, for a fixed size of repair. The presence of load transfer devices in nine-slab model beneficially reduced both the maximum $S_{1}$ and $\sigma$ regardless of the kinds of repair materials used. Furthermore, the plot of variation in stress versus size of repair obtained using the nine-slab model was similar to that obtained using the single slab model.

The low-stress proportions of $S_{1}$ and $\sigma^{\prime}$ obtained using the nine-slab model were larger than those obtained using the single slab model. The plot of variation in low-stress proportions against side length of repair obtained using both models was similar. The presence 


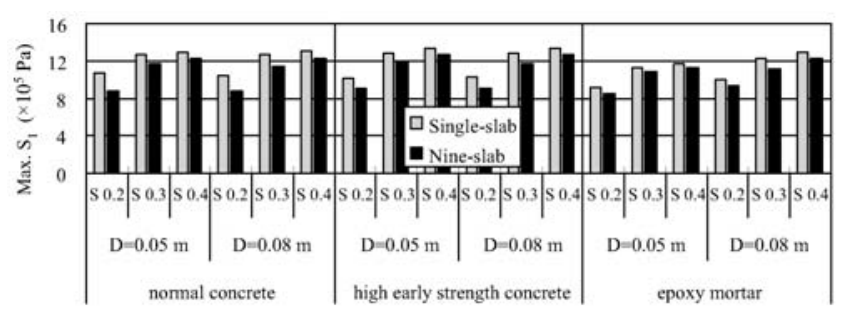

(a) Maximum $\mathrm{S}_{1}$

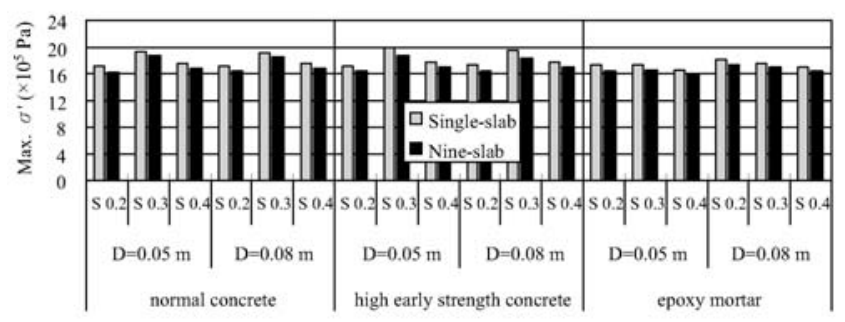

(b) Maximum $\sigma^{\prime}$

Fig. 7. Comparison for maximum stresses obtained from single-slab model and nine-slab model.

of load transfer devices helped to increase the lowstress proportions of $\sigma^{\prime}$ when the repair was shallow.

\section{DISCUSSIONS}

This study was based on linear-elastic 3D finite element analysis, and emphasized variations of stress distributions that were independent of failure behaviors. The size, depth and shapes of the areas of repair as well as the repairing materials were the main variables in the analyses, under constant loading conditions. The items associated with $S_{1}$ and $\sigma^{\prime}$ were used to predict the distribution of stress in the partial-depth repair. If one item promoted repair but another did not, the settings were considered not to be beneficial to repair.

The results obtained from the single slab model and the nine-slab model were similar in trend, but not in magnitude. The maximum stresses determined using the nine-slab model were smaller than those determined by the single slab model, implying that the single slab model for partial-depth repair is conservative, but good enough to represent in situ behavior after repairs.

When epoxy mortar was used to make repairs with square or triangular areas, $S_{1}$ was maximum on the bottom of the area of repair, which was the horizontal interface between the epoxy mortar and original concrete. When a wheel load was applied to the repaired area, the stress on the bottom of the area should be compressive rather than tension, as expected. This unusual phenomenon might be attributable to the high

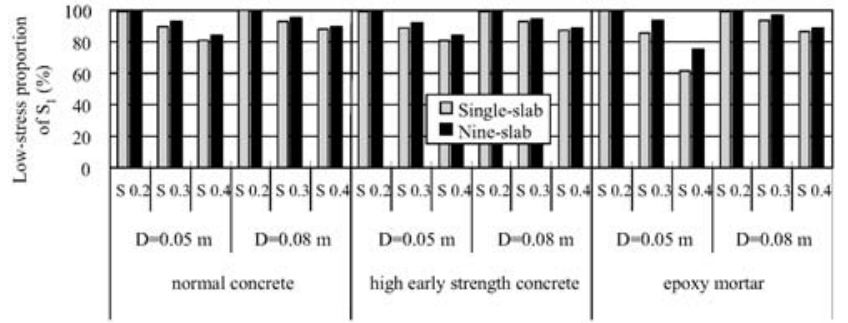

(a) Low-stress proportion of $\mathrm{S}_{1}$

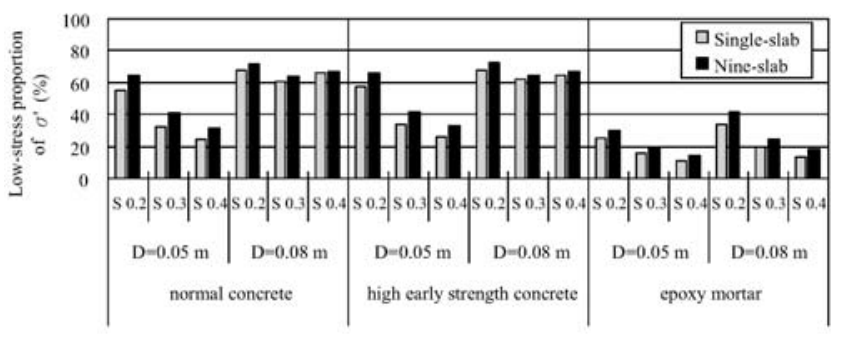

(b) Low-stress proportion of $\sigma^{\prime}$

Fig. 8. Comparison for low-stress proportions obtained from singleslab model and nine-slab model.

Poisson ratio of the epoxy mortar used herein.

\section{CONCLUSIONS}

When cementitious repairing materials were used, the square area of repair seemed to yield better repairs when depth rather than area was increased, because low-stress proportions increased with the depth of the repairs. In small repairs with a small side length, less than $0.2 \mathrm{~m}$, triangular and spherical areas resulted in better stability, because the stresses were lower and the low-stress proportions were larger. However, when side length of the area of repair was larger than $0.2 \mathrm{~m}$, the use of a spherical repairing area was not recommended.

The material properties of epoxy mortar as a repairing material differed significantly from those of the original concrete. Predicting the stress behavior following repairs was difficult because the analysis of the results was complex. Epoxy mortar was not a good repairing material for square areas of repair, but was acceptable for small spherical repairs. The use of epoxy mortar was preferred for shallow repairs over deep ones.

\section{ACKNOWLEDGEMENT}

The authors would like to thank the Taiwan Area National Freeway Bureau for financially supporting this research under Contract No. 088B5AS003B5A004. 


\section{REFERENCES}

1. ANSYS User's Manual V5.5: Elements Reference, Swanson Analysis Systems, Inc., Canonsburg, PA (1998).

2. Brill, D.R., Field Verification of a 3D Finite Element Rigid Airport Pavement Model, Report DOT/FAA/AR00/33. FAA, U.S. Department of Transportation (2000).

3. Channakeshava, C. and Barzegar, F., "Nonlinear FE Analysis of Plain Concrete Pavements with Doweled Joints," J. Transp. Eng., Vol. 119, No. 5, pp. 763-781 (1993).

4. Chatti, K., "Dynamic Analysis of Jointed Concrete Pavements Subject to Moving Transient Load," Ph.D. Dissertation, Institute of Transportation Studies, University of California at Berkeley (1992).

5. Collins, J.A., Failure of Materials in Mechanical Design, John Wiley and Sons, Inc., New York (1993).

6. Concrete Paving Technology-Guidelines for PartialDepth Spall Repair, TB-003.02P, American Concrete Pavement Association, Skokie, IL (1998).

7. Cook, R.D., Malkus, D.S., Plesha, M.E., and Witt, R.J., Concepts and Applications of Finite Element Analysis, John Wiley and Sons, Inc., New York (2002).

8. Darter, M.I., Barenberg, E.J., and Yrjanson, W.A., Joint Repair Methods for Portland Cement Concrete Pavement, National Cooperative Highway Research Program Report 281, Transportation Research Board, National Research Council, Washington, D.C. (1985).

9. Easa, S.M., Strauss, T.R., Hassan, Y., and Souleyrette, R.R., "Three-Dimensional Transportation Analysis: Planning and Design," J. Transp. Eng., ASCE, Vol. 128, No. 3, pp. 250-258 (2002).

10. Furr, H.L., Highway Uses of Epoxy with Concrete, NCHRP Synthesis of Highway Practice 109, Transportation Research Board, National Research Council, Washington, D.C. (1984).

11. Huang, Y.H., Pavement Analysis and Design, Prentice Hall, New Jersey (1993).

12. Ioannides, A.M. and Donelly, J.P., "Three-Dimensional Analysis of Slab on Stress-Dependent Foundation,"
Transp. Res. Rec. 1196, TRB, National Research Council, Washington, D.C., pp. 72-84 (1988).

13. Ioannides, A.M. and Korovesis, G.T., "Analysis and Design of Doweled Slab-on-Grade Pavement Systems," J. Transp. Eng., ASCE, Vol. 118, No. 6, pp. 745-768 (1992).

14. Jiang, S.L., "Optimum Repairing Section for Corner Failure in Concrete Pavement," Master Thesis, Department of Civil Engineering, National Central University, Taiwan (2000). (in Chinese)

15. Kuo, C.M., "Three-Dimensional Finite Element Analysis of Concrete Pavement," Ph.D. Dissertation, University of Illinois at Urbana (1994).

16. Massad, A., Taha, R., and Muhunthan, B., "Finite Element Analysis of Temperature Effects on Plain Jointed Concrete Pavements," J. Trans. Eng., ASCE, Vol. 122, No. 5, pp. 388-398 (1996).

17. McGhee, K.H., Design, Construction, and Maintenance of PCC Pavement Joints, NCHRP Synthesis of Highway Practice 211, Transportation Research Board, National Research Council, Washington, D.C. (1995).

18. Patel, A.J., Mojab, C.A.G., and Romine, A.R., Materials and Procedures for Rapid Repair of Partial-Depth Spalls in Concrete Pavements-Manual of Practice, Strategic Highway Research Report No. SHRP-H-349, National Research Council, Washington, D.C. (1993).

19. Shoukry, S.N., Fahmy, M., Prucz, J., and William, G., "3D Finite Element Modeling of Rigid Pavement Response to Moving Load and Nonlinear Temperature Gradient," Proceedings of the Third International Symposium on 3D Finite Element Modeling for Pavement Analysis and Design, Amsterdam, The Netherlands, pp. 401-422 (2002).

20. White, D., Synthesis of Current and Projected Concrete highway Technology, Strategic Highway Research Report No. SHRP-C-345, National Research Council, Washington, D.C. (1993).

21. Yu, T., Concrete Rehabilitation-Users Manual, Strategic Highway Research Report No. SHRP-C-412, National Research Council, Washington, D.C. (1994). 